\title{
Dose-dependent responses of metabolism and tissue injuries in clam Ruditapes philippinarum after subchronic exposure to cadmium
}

\author{
Junfei Zhan ${ }^{\mathrm{a}, \mathrm{d}}$, Shuang Wang ${ }^{\mathrm{a}, \mathrm{d}}$, Fei $\mathrm{Li}^{\mathrm{a}, \mathrm{c}}$, Chenglong Ji ${ }^{\mathrm{a}, \mathrm{b}, \mathrm{c}}$, Huifeng Wu ${ }^{\mathrm{a}, \mathrm{b}, \mathrm{c}, *}$

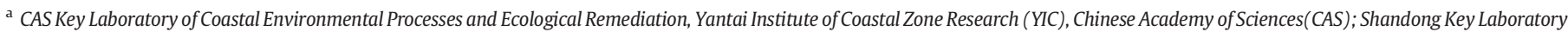 \\ of Coastal Environmental Processes, YICCAS, Yantai Shandong 264003, PR China \\ b Laboratory for Marine Fisheries Science and Food Production Processes, Qingdao National Laboratory for Marine Science and Technology, Qingdao 266237, PR China \\ c Center for Ocean Mega-Science, Chinese Academy of Sciences (CAS), Qingdao 266071, PR China \\ ${ }^{\mathrm{d}}$ University of Chinese Academy of Sciences, Beijing 100049, PR China
}

\section{H I G H L I G H T S}

- Cd exposure resulted in both monotonic and non-monotonic responses in clams.

- The key enzymes hexokinase and citrate synthase presented monotonic decreases.

- Succinate and SDH presented typical hormetic dose-response curves.

- Hepatopancreas was more sensitive than gills to $\mathrm{Cd}$ in terms of injury occurrence.

- Glutamine and citrate synthase presenting monotonic curves were preferable biomarkers.

\section{A R T I C L E I N F O}

\section{Article history:}

Received 23 December 2020

Received in revised form 5 March 2021

Accepted 11 March 2021

Available online 16 March 2021

Editor: Michael Norman Moore

\section{Keywords:}

Cadmium

Dose-response

Hormesis

Metabolomics

Ruditapes philippinarum

Tissue injuries

\section{G R A P H I C A L A B S T RACT}

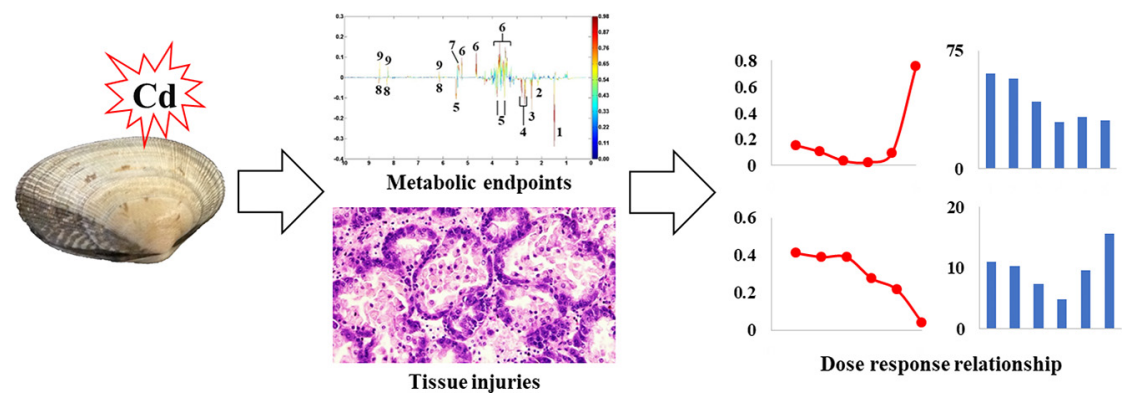

Abbreviations: AIC, Akaike information criterion; ALT, alanine aminotransferase; AMP, adenosine monophosphate; ANOVA, analysis of variance; ATP, adenosine triphosphate; BCA,

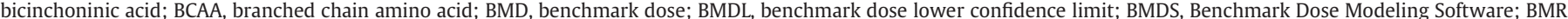

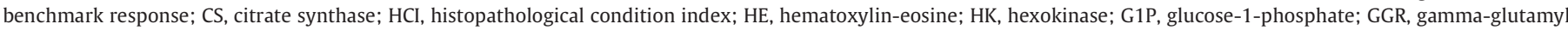

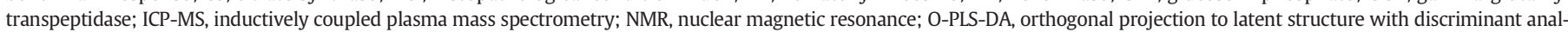
ysis; OXPHOS, oxidative phosphorylation; PCA, principal components analysis; PK, pyruvate kinase; SDH, succinate dehydrogenase; TCA, tricarboxylic acid.

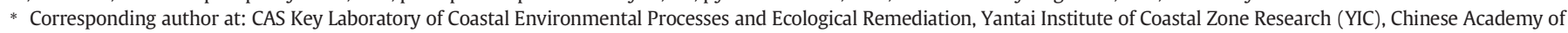
Sciences (CAS), Yantai 264003, PR China.

E-mail address: hfwu@yic.ac.cn (H. Wu). 
typical hormetic dose-response curves. What is more, clam hepatopancreas was more sensitive to $\mathrm{Cd}$ than gill in terms of injury occurrence. Overall, characterization of dose-dependent effect of $\mathrm{Cd}$ on metabolism and tissue injuries provides a new insight into understanding the metabolic adaptation in marine clams and risk assessment of Cd pollution.

\section{Introduction}

Cadmium (Cd) pollution is regarded as one of the emerging priority issues of United Nations Environment Programme (UN Environment Programme, 2020). As a non-essential metal element for organism, Cd accumulation to a certain extent tends to induce toxicities and pose risk on health (Du et al., 2021). Marine Cd pollution has been globally occurring because of industrial effluents and river discharge. Our recent investigations on marine organisms sampled from the Bohai Sea revealed that $\mathrm{Cd}$ was one of the most frequently detectable metal contaminants (Ji et al., 2016; Xu et al., 2016). The increasing detection of Cd is of considerable environmental concern, which creates a pressing need to characterize toxicological effects and develop biomarkers of $\mathrm{Cd}$. Though biomarkers have the potentials in monitoring and risk assessment, they also face challenges because of dose-response relationships between $\mathrm{Cd}$ doses and biological responses.

Dose-response is the backbone of toxicology, and the dose-response relationship is the key in understanding how many adverse effects can be induced to organisms, as well as the tolerance capacity of organisms to stressors (Agathokleous and Calabrese, 2019). In general, the relationship presents not only monotonic responses like linear, power, exponential curves, but also non-monotonic responses like U-shaped and J-shaped curves (or inverted U-shaped and inverted J-shaped curves, depending on the endpoints) (Agathokleous, 2018). Undoubtedly, the endpoints with monotonic responses are potential biomarkers to indicate stresses. However, the effects of high doses cannot be predicted by the effects observed at low doses in non-monotonic curves. What is more, as a special dose response, hormesis is a biphasic doseresponse phenomenon characterized by a low-dose stimulation and a high-dose inhibition (Calabrese, 2008; Agathokleous, 2018). Increasing evidence shows that hormesis is a highly generalized dose-response phenomenon in animals, plants and microbes (Calabrese et al., 2019). Ignoring dose-response relationships therefore is not the ideal methodology for not only characterizing toxicity but also selecting biomarkers.

Metabolism homeostasis plays essential roles in organism's survival and function, as well as in stress adaptation and tolerance (Sokolova et al., 2012). Metabolic processes, such as tricarboxylic acid (TCA) cycle, glycolysis, and oxidative phosphorylation (OXPHOS) are frequently identified as the targets of Cd (Sokolova et al., 2005b; Ji et al., 2019). However, these researches failed to reveal the dose-dependent effects of $\mathrm{Cd}$ because of lacking adequate number of $\mathrm{Cd}$ doses. So far, studies on dose-responses between $\mathrm{Cd}$ and metabolism are relatively limited. Ivanina et al. (2008) observed U-shaped dose-response curves in mitochondrial enzymes in Cd-treated oysters. Metabolomics can identify and quantify metabolic products of a biological system, and has been increasingly used in ecotoxicological studies to evaluate the toxicological effects of contaminants (Xie et al., 2020). In our recent work, metabolome profiles in Perinereis aibuhitensis were used to investigate the dose response of metabolites, demonstrating that $\mathrm{Cd}$ induced multiple dose-responses at metabolite level (Liu et al., 2019). These researches confirmed the existence of dose-dependent effects of $\mathrm{Cd}$ on metabolism.

Marine clam Ruditapes philippinarum is an economically and scientifically important bivalve. Due to its wide distribution, ease of collection, low mobility, and filter-feeding, $R$. philippinarum has been frequently used to characterize the adverse effects of multiple contaminants (Chen et al., 2018; Wu et al., 2013) and biomonitor marine pollution (Krishnakumar et al., 2018). As clams are unable to escape from stresses and must adapt to variable environments, metabolic adaptation in clams is therefore of great importance. Dose-responses between Cd exposure and metabolic endpoints are essential for understanding how clams respond and when metabolic transitions occur. In this work, as described in the flowchart of experimental design (Fig. S1), we characterized metabolomic profiles and measured metabolic enzymes in whole soft tissues of clams from a serial of $\mathrm{Cd}$ exposure groups, aiming to reveal the dose-dependent effect of $\mathrm{Cd}$ on metabolism in clams. The calculation of histopathological condition indices (HCIs) was also conducted on clam gills and hepatopancreas to quantify the tissue injuries. Benchmark dose (BMD) is U.S. Environment Protection Agency (U.S. EPA) preferred methodology for dose-response analysis. The BMD value is determined as a dose level associated with a specified change in benchmark response (BMR) (Hardy et al., 2017). By model fitting, the BMD values of endpoints were calculated. Sensitive biomarkers were selected based on lower BMD values. We hypothesized that Cd treatments could induce not only monotonic responses but also nonmonotonic responses in metabolic processes in clams. As hormesis is regarded as an overcompensation response following an initial disruption in homeostasis (Calabrese, 2008), we also hypothesized that hormesis was present during metabolism homeostasis in response to $\mathrm{Cd}$ stress. The investigation on dose dependence of $\mathrm{Cd}$ will provide a new insight into understanding the metabolic adaptation in marine clams and risk assessment of $\mathrm{Cd}$ pollution.

\section{Materials and methods}

\subsection{Animals and exposure conditions}

Adult clams R. philippinarum (shell length: $3.5-3.8 \mathrm{~cm}$, White pedigree) were purchased from an aquaculture farm (Qingdao, China). The exposure experiment was conducted according to Ji et al. (2019). After transported to laboratory, clams were acclimated in aerated seawater for 5 days, and then randomly divided into 6 groups, including control group and $5 \mathrm{Cd}$-treated groups. Each group contained two replicate tanks, each of which consisted of 15 individuals in 15 L filtered seawater (FSW). Control clams were kept in FSW. Cd exposure concentrations included 3, 9, 27, 81, and $243 \mu \mathrm{g} / \mathrm{L}$, of which 3, 9 and $27 \mu \mathrm{g} / \mathrm{L}$ were environmentally relevant (Fu et al., 2014; Zhang et al., 2010) and $243 \mu \mathrm{g} / \mathrm{L}$ referred to nearly $20 \%$ of $96-\mathrm{h} \mathrm{LC}_{50}$ of Cd to R. philippinarum $(1360 \mu \mathrm{g} / \mathrm{L})$. The stock solutions of $\mathrm{CdCl}_{2}$ were prepared by dissolving analytical reagent grade $\mathrm{CdCl}_{2}$ in deionized water. During the acclimation and exposure periods, clams were kept in aerated seawater $\left(25 \pm 2{ }^{\circ} \mathrm{C}, 31 \mathrm{psu}\right)$ under a photoperiod of $12 \mathrm{~h}$ light and $12 \mathrm{~h}$ dark, fed with Chlorella vulgaris of $2 \%$ tissue dry weight once daily. Exposure seawater was completely replaced by fresh seawater daily. After exposure for 14 days, 4 clams were selected for histopathological analysis on gills and hepatopancreas, and another 9 clams were selected for measurements of $\mathrm{Cd}$ accumulation, enzymes activities and metabolomic profiles. Of the 9 clams, the whole soft tissue of each individual was ground to powder in liquid nitrogen. Each sample was then divided into 3 parts for simultaneous measurement of $\mathrm{Cd}$ accumulation, enzymes activities and metabolomic profiles.

\subsection{Measurement of Cd accumulation in whole soft tissues of clams}

Cd accumulation in clams was measured according to the description by Wu and Wang (2010). In details, the whole soft tissue samples 
( $n=9$ ) of clams were dried at $80^{\circ} \mathrm{C}$ to constant weights, which were recorded for calculation of $\mathrm{Cd}$ accumulation. The dried samples were then digested in concentrated nitric acid (70\%, Fisher Scientific) heated in water bath overnight. All completely digested samples were diluted with ultrapure water for the determination of Cd using inductively coupled plasma mass spectrometry (ICP-MS) technique (Agilent 7500i, Agilent Technologies Co. Ltd., Santa Clara, CA, USA). The limit of quantification (LOQ) of Cd was $0.1 \mathrm{ppb}$, which was at least two orders of magnitude lower than those detected in control clam samples. Marine mussel tissue standard reference material (GBW08571) was employed as a certified reference material for metal analysis to ensure internal quality assurance/quality control $(\mathrm{QA} / \mathrm{QC})$ practices. The recovery of target elements, as tested by three individual spiking experiments, was restricted within $95.5 \%-104.3 \%$ for Cd.

\subsection{Metabolomic analysis}

Nuclear magnetic resonance (NMR)-based metabolomics was used to unravel the alterations of metabolites in clams treated with $\mathrm{Cd}$. Polar metabolites in clam whole body $(n=9)$ were extracted in $4 \mathrm{~mL} / \mathrm{g}$ of methanol, $5.25 \mathrm{~mL} / \mathrm{g}$ of water and $2 \mathrm{~mL} / \mathrm{g}$ of chloroform as described previously and analyzed on a Bruker AV 500 NMR spectrometer performed at $500.18 \mathrm{MHz}$ (at $25^{\circ} \mathrm{C}$ ) as described previously (Wu and Wang, 2010).

All one dimensional ${ }^{1} \mathrm{H}$ NMR spectra were converted to a data matrix using the custom-written ProMetab software in Matlab version 7.0 (The MathWorks, Natick, MA, USA) and then segmented into bins with a width of $0.005 \mathrm{ppm}$ between 0.2 and $10.0 \mathrm{ppm}$. All the NMR spectra were generalized log transformed with a transformation parameter $\lambda=1.0 \times 10^{-8}$ and subsequently data were mean-centered before data analysis. The unsupervised multivariate data analysis methods, principal components analysis (PCA), was performed to detect the global dose-dependent response profiles related to $\mathrm{Cd}$ exposures. The supervised multivariate data analysis methods, orthogonal projection to latent structure with discriminant analysis (O-PLS-DA), were sequentially carried out to uncover and extract the statistically significant metabolite variations related to $\mathrm{Cd}$ treatments. Metabolites were identified by using the software, Chenomx (Evaluation Version, Chenomx Inc., Edmonton, Alberta, Canada). The metabolite concentrations ( $\mathrm{mM}$ ) were determined based on the concentration $(0.5 \mathrm{mM})$ of internal standard, TSP.

\subsection{Metabolic enzymes in response to $\mathrm{Cd}$ treatments}

The activities of 6 typical enzymes related to metabolism, including hexokinase (HK, EC: 2.7.1.1), pyruvate kinase (PK, EC: 2.7.1.40), citrate synthase (CS, EC: 2.3.3.1), succinate dehydrogenase (SDH, EC: 1.3.5.1), gamma-glutamyl transpeptidase (GGT, EC: 2.3.2.2) and alanine aminotransferase (ALT, EC: 2.6.1.2), were measured in the whole soft tissue of clams from control and Cd-exposed groups. The whole soft tissue of clams $(n=9)$ ground under liquid nitrogen was firstly homogenized by adding normal saline or enzyme-specific homogenization buffers provided by enzyme kits (Nanjing Jiancheng Bioengineering Institute, Nanjing, China). The activities of CS (Else et al., 1988), GGT (Meister et al., 1981) and ALT (Wilkinson et al., 1972) were assayed using a UV-vis spectrophotometer (U3900H, HITACHI), and the measurement of SDH (Burke et al., 1982), HK (Scheer et al., 1978) and PK (Gutman and Bernt, 1974) activities was conducted using a microplate reader (Infinite M200, TECAN) according to the manufacturer's protocols for enzyme kits (Nanjing Jiancheng Bioengineering Institute, Nanjing, China). The concentrations of total protein in homogenates were determined by bicinchoninic acid (BCA) method with bovine serum albumin as standard. The unit of HK, CS and SDH was defined as the activity of an enzyme per milligram protein (U/mg protein), and the unit of PK, GGT and ALT was defined as the activity of an enzyme per gram protein (U/g protein).

\subsection{Histopathological observations}

After immediate dissection from the clams, gill and hepatopancreas tissues $(n=4)$ were fixed in the Bouin's fixative solution for $24 \mathrm{~h}$, followed by dehydrated in a progressive series of ethanol and embedded in paraffin. Tissues from control and $\mathrm{Cd}$ exposure groups were processed together in batches to remove artefacts. Histological sections (6-8 $\mu \mathrm{m}$ thickness) were cut from the paraffin embedded tissues and mounted on slides which were stained with hematoxylin-eosine (HE) and observed under a light microscope (Olympus BX61, Tokyo, Japan) at $\times 200$ magnification (zoom on the camera was $\times 2.5$ ).

The degree of pathological lesion was evaluated through the histopathological condition index $(\mathrm{HCI})$ based on the weighted indices approach (Bernet et al., 1999; Costa et al., 2013). In brief, HCI was calculated by the biological significance of each surveyed alteration (weight) and its degree of dissemination (score). The weight value ranges from 1 (minimal significance) to 3 (maximum severity), and the score value ranges from 0 (no observed alteration) to 6 (diffusion). A total of 20 candidates of histopathological alterations were selected and listed in Table S1. The HCI was calculated according to the formula:

$I_{h}=\frac{\sum_{1}^{j} w_{j} a_{j h}}{\sum_{1}^{j} M_{j}}$

where $I_{h}$ is the histopathological condition indices for the individual h; $w_{j}$ is the weight of the $j$ th histopathological alteration; $a_{j h}$ is the score of the jth alteration for the individual $h$ and $M_{j}$ is the maximum attributable value for the $j$ th alteration (weight $\times$ maximum score).

\subsection{BMD modeling}

A BMD is a dose or concentration that produces a predetermined change in the response rate of an adverse effect. This predetermined change in response is called the benchmark response (BMR). In this work, a default BMR of 1 standard deviation (relative to control) was used for all datasets, including metabolites, enzyme activities, and HCIs. By using Benchmark Dose Modeling Software (BMDS) version 3.1.1 by U.S. EPA, automated BMD modeling analysis was performed on these endpoints to fit the best model and calculate BMD values of endpoints. A series of models, including Linear, Polynomial, Power, Hill, Exponential (M2, M3, M4, M5), were used to model the datasets. Models were initialized using BMDS 3.1.1 model defaults. The selection of models was relied on the model recommendation decision logic (Fig. S2) (US EPA, 2012; Wignall et al., 2014). In brief, the model in viable bin was taken into consideration. The only candidate model in the viable model bin was of course deemed as the best-fit model. If the viable bin had more than one model, lowest Akaike information criterion (AIC) or lowest benchmark dose lower confidence limit (BMDL) was selected. If the range of BMDL values was sufficiently close (less than 3-fold different), the AIC value was used; otherwise, the BMDL value was used. If no viable model was recommended, model in questionable bin was also considered and selected according to the selection criterion of model in viable bin. The details of models and selection criteria of best-fit models were available in Supporting information.

\subsection{Statistical analysis}

The endpoints, including Cd concentrations, metabolites, enzymes activities, and HCIs in clams, were expressed as means \pm standard deviation and tested for normal distribution (Ryan-Joiner's test) and homogeneity of variances (Bartlett's test). One way analysis of variance (ANOVA) followed by Dunnett's test was performed on these endpoints from control and Cd-treated groups. The $P$ value less than 0.05 was considered statistically significant. Statistical analyses were conducted using R software (Version 3.6.3). 


\section{Results}

\subsection{Cd accumulation in clams}

After exposure to $\mathrm{Cd}$ for 14 days, $\mathrm{Cd}$ contents in whole soft tissues from $\mathrm{Cd}$ treatments ranged from 4.76 to $46.06 \mu \mathrm{g} / \mathrm{g}$ dry weight (dw) with the increase of $\mathrm{Cd}$ dose (Fig. 1). Compared with Cd contents in control group, significant accumulation $(P<0.05)$ of $C d$ was observed in 9 , 27,81 , and $243 \mu \mathrm{g} / \mathrm{L}$ Cd-treated groups. Cd accumulation in clam whole soft tissues occurred under even environmentally relevant concentrations ( 9 and $27 \mu \mathrm{g} / \mathrm{L}$ ) of $\mathrm{Cd}$, which potentially imposed adverse effects on clams.

\subsection{The response of metabolic enzyme activities in clams}

The activities of six typical enzymes associated with metabolism were changed in clams treated with $\mathrm{Cd}$. As shown in Fig. 2, the activities of SDH and ALT in clams showed nearly U-shaped curves with bottoms at $\mathrm{Cd}$ dose of $27 \mu \mathrm{g} / \mathrm{L}(P<0.05)$. GGT activity presented a J-shaped curve with bottom at Cd dose of $9 \mu \mathrm{g} / \mathrm{L}$. HK activity decreased under low concentrations of $\mathrm{Cd}$ treatments and remained unchanged with increasing $\mathrm{Cd}$ dose. CS activity linearly decreased with the increase of Cd dose except for that in $243 \mu \mathrm{g} / \mathrm{L}$ Cd-treated group. PK activity presented multiphase responses similar to U-shaped curve.

\subsection{The response of metabolomic profiles in clams}

A total of 33 metabolites in the whole soft tissues of clams were identified and labeled in Supporting information Fig. S3. In order to investigate the global dose-dependent responses of metabolomic profiles, PCA analysis was conducted on the NMR spectral data from control and Cd-treated groups. As shown in Fig. 3, the average scores along PC1 accounted for $49.84 \%$ variation presenting an inverted U-shaped curve, followed by PC2 (20.32\% variation) and PC3 (7.78\% variation) showing linearly increased and U-shaped curves, respectively, suggesting multiple dose-response relationships between metabolites in clams and Cd dose.

O-PLS-DA demonstrated the significant $(P<0.05)$ metabolic differences between clam samples from control group and $5 \mathrm{Cd}$-treated groups with reliable $Q^{2}$ values of $0.364,0.663,0.948,0.929$, and 0.966 .
The loading plots showed responsive metabolites in two typical Cdtreated groups (27 and $243 \mu \mathrm{g} / \mathrm{L} \mathrm{Cd}$ treatments) (Fig. 4). A total of 15 metabolites were identified to be changed in response to $\mathrm{Cd}$ treatments (Table S2). In general, the altered metabolites varied among Cd-treated groups, and the number of altered metabolites increased with the increase of $\mathrm{Cd}$ exposure dose. In details, Cd treatments induced upregulation of 10 metabolites, of which glucose was commonly altered in all Cd-treated groups, and ATP was significantly changed only in 9, 27 , and $81 \mu \mathrm{g} / \mathrm{L}$ Cd-treated groups. Glycogen increased at 3, 9, 27, and $81 \mu \mathrm{g} / \mathrm{L} \mathrm{Cd}$-treated groups and decreased at the highest concentration $(243 \mu \mathrm{g} / \mathrm{L})$ of Cd-treated group. Moreover, a set of increased metabolites, including branched chain amino acids (BCAAs), choline, glutamate, and phenylalanine were uniquely observed in $243 \mu \mathrm{g} / \mathrm{L} \mathrm{Cd}$-treated clams. Cd treatments also induced down-regulations of 8 metabolites, including alanine, glucose-1-phosphate (G1P), AMP, glutamine, succinate, threonine, fumarate, and glycogen. G1P was the only metabolite commonly down-regulated in all Cd-treated groups. Decrease of alanine was elicited in all Cd-treated groups. Glutamine decreased only in three high concentrations (27, 81, and $243 \mu \mathrm{g} / \mathrm{L})$ of Cd-treated groups.

Quantification was conducted on 7 commonly altered metabolites to evaluate the dose-dependent effect of $\mathrm{Cd}$ on clam metabolites (Fig. 5 , Table 1). Glucose and ATP presented responses approximate to inverted U-shaped curves with top at dose of $9 \mu \mathrm{g} / \mathrm{L}$, which were consistent with the curve along PC1 axis. The responsive profiles of alanine and AMP showing U-shaped curves were similar to the curve along PC3 axis. Succinate showed a typical J-shaped curve. Glutamine gradually decreased when Cd exposure dose exceeded $9 \mu \mathrm{g} / \mathrm{L}$.

\subsection{Histopathological alterations in clam gills and hepatopancreas}

In control group, clams presented normal gills, including intact gill filaments and regular epithelial cells, which were also observed in 3 and $9 \mu \mathrm{g} / \mathrm{L}$ Cd-treated clams (Fig. 6). By comparison, 27 and $81 \mu \mathrm{g} / \mathrm{L} \mathrm{Cd}$ treatments induced vacuole and reduction of epithelial cells in gill filaments. Moreover, irregular shape of gill filaments and decrease of frontal cilia and lateral cilia were found in $81 \mu \mathrm{g} / \mathrm{L}$ Cd-treated clams. In the highest concentration $(243 \mu \mathrm{g} / \mathrm{L}) \mathrm{Cd}$-treated group, clams showed totally abnormal gill filaments and necrosis in gills. Cd treatment elicited similar histological changes in hepatopancreas. Normal shape of digestive tubule consisting of regular epithelial cells and intact tubular

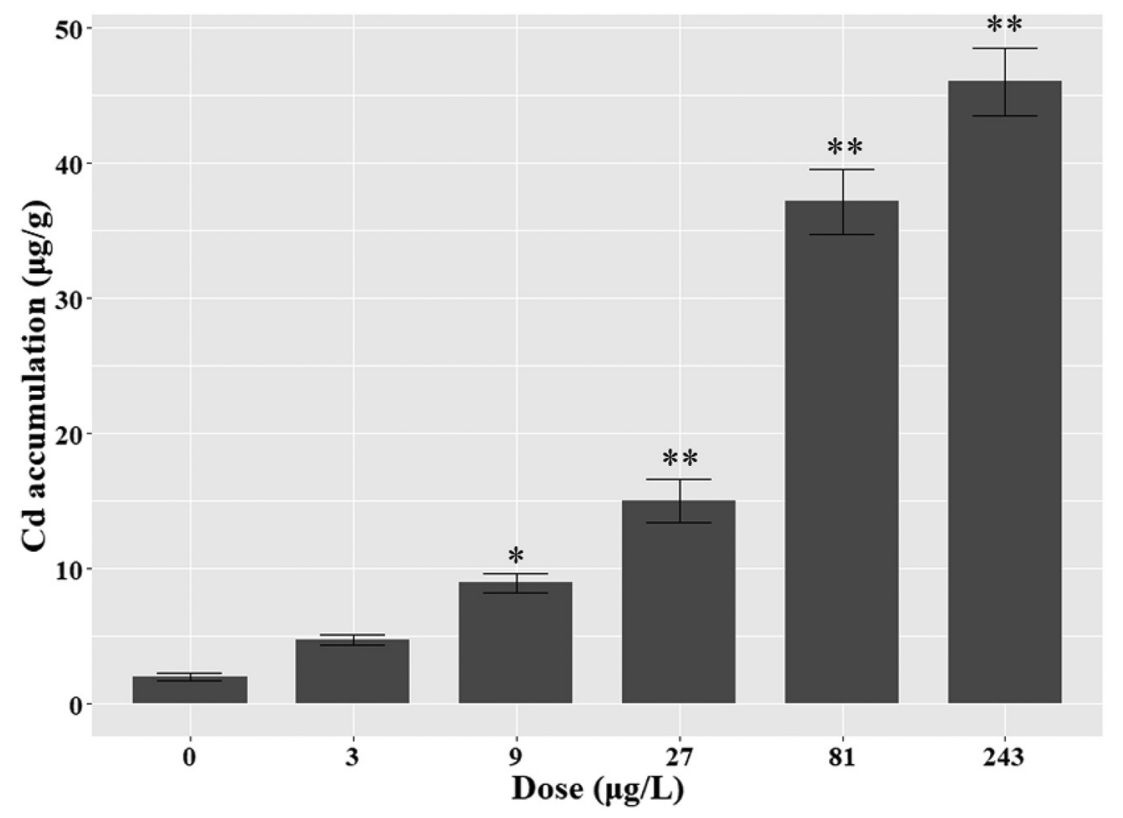

Fig. 1. The concentrations of $\mathrm{Cd}$ in clams. ${ }^{*}$ and ${ }^{* *}$ indicate significant differences $(P<0.05$ and $P<0.01)$ between control and $C d$ treatment groups. 

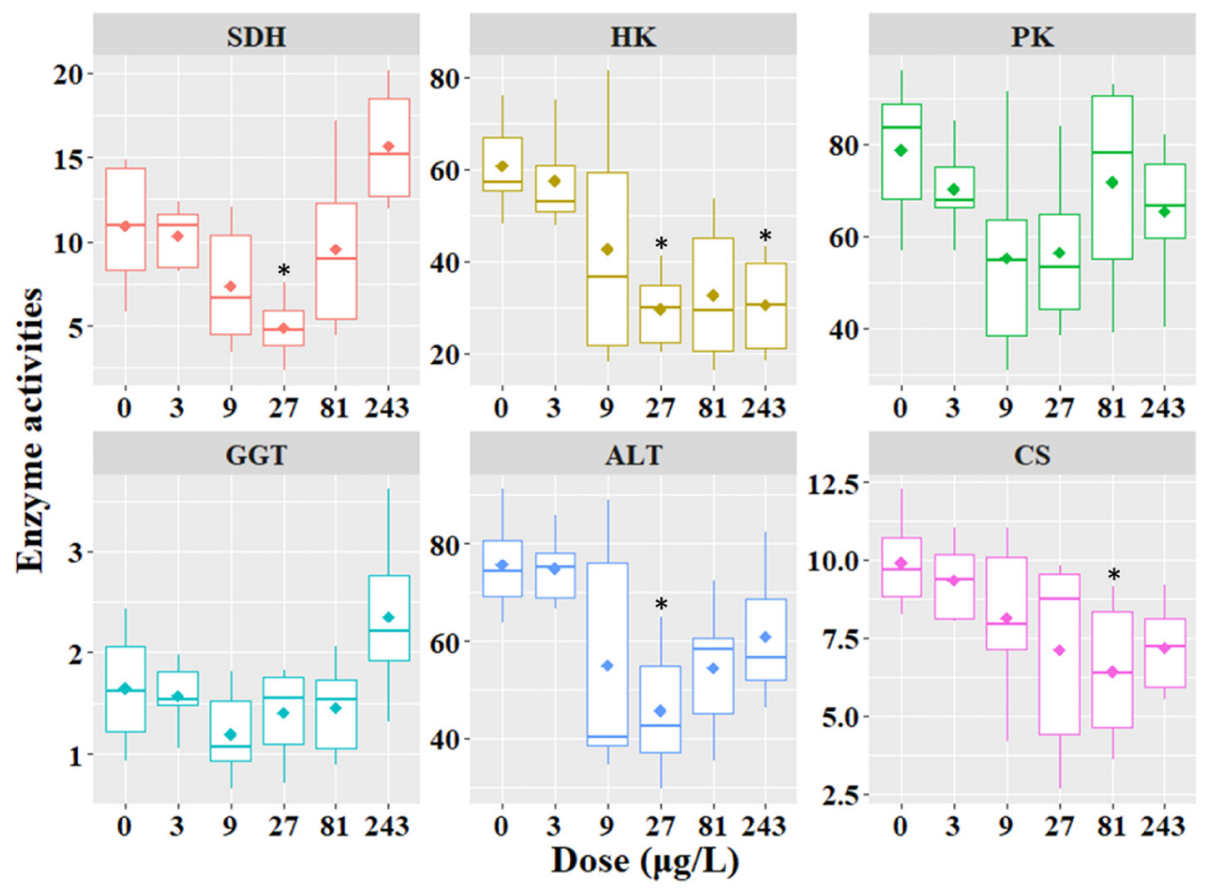

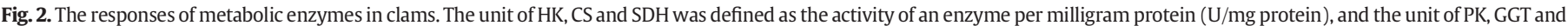

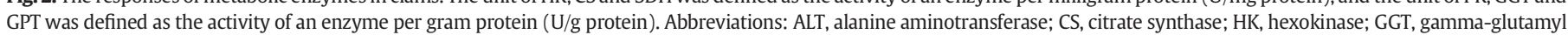
transpeptidase; PK, pyruvate kinase; SDH, succinate dehydrogenase. ${ }^{*}$ and ${ }^{* *}$ indicate significant differences $(P<0.05$ and $P<0.01)$ between control and Cd treatment groups.

lumen was found in control group as well as 3 and $9 \mu \mathrm{g} / \mathrm{L}$ Cd-treated group. In $27 \mu \mathrm{g} / \mathrm{L}$ Cd-treated group, Cd treatment swelled epithelial cells and narrowed tubular lumens. Most of epithelial cells showed irregular shapes and even atrophy in clams treated with $81 \mu \mathrm{g} / \mathrm{L} \mathrm{Cd}$. In the highest concentration ( $243 \mu \mathrm{g} / \mathrm{L}$ ) of Cd-treated group, necrosis of digestive tubule appeared in clam hepatopancreas, and numerous haemocytes infiltrated the damaged gland.

The pathological lesions were quantified by calculating HCIs in gills and hepatopancreas. In general, the HCIs presented an increase trend with the increase of $\mathrm{Cd}$ dose. Both gills and hepatopancreas did not show significant alteration of $\mathrm{HCls}$ until the $\mathrm{Cd}$ exposure concentration reached up to $27 \mu \mathrm{g} / \mathrm{L}$.

\subsection{BMD estimation}

In this work, BMD analysis was performed on the endpoints including metabolites, enzyme activities, and HCIs (Table 1). According to the best-fit models, BMD and BMDL values were calculated. A representative response curve of CS activities fitting to Hill model was available in Fig. S4. Of 7 metabolites, only glutamine was fitted to Hill model with BMD value of 17.87, whereas the rest failed to be fitted to viable models. Concerning the enzymes, GGT and ALT activities were commonly fitted to Exp4 model, while CS activity was fitted to Hill model. PK, SDH, and HK activities failed to be fitted to viable models under BMDS selection criteria. CS activity showed the lowest BMD value (10.67), followed by ALT activity (20.07) and GGT activity (209.92). Furthermore, the HCIs of gills and hepatopancreas were best fitted to the Exp5 and Hill models, respectively. BMD analysis demonstrated that BMD value of hepatopancreas HCIs (8.32) was less than those of gill HCIs (11.11).

\section{Discussion}

As it is known, exposure to pollutants may increase the energy demand for detoxification, demand repair, and/or decrease energy production (Noor et al., 2021). Severer stresses potentially induce impacts on the aerobic pathways producing ATP by inhibiting metabolic enzymes and reducing assimilation of food. Therefore, organisms under stresses have to re-arrange metabolic strategy to meet the increasing energy demand as well as adapt the decreasing energy supply. In this work, we found that the responses of metabolites and metabolic enzymes associated with glycolysis, TCA cycle, amino acid metabolism/ synthesis, and OXPHOS presented both monotonic and non-monotonic curves with the increase of Cd dose (Fig. 7). The monotonic responses suggested consistent disruption of $\mathrm{Cd}$ on metabolism and were potential biomarkers to Cd stress, while non-monotonic responses seemed to reflect the adaptive strategy of metabolic responses in clams.

\subsection{Monotonic metabolic responses to $\mathrm{Cd}$}

Monotonic responses occurred in both enzymes (HK and CS) and metabolites (glutamine and G1P). HK is the initial as well as one of the rate-limiting enzymes of glycolysis (Lin and $\mathrm{Xu}, 2016$ ). The monotonic inhibition of HK activity was explained as irreversible damage to the enzymes (Ramírez-Bajo et al., 2014). Glycolysis is highly regulated by the phosphorylation of glucose by HK, and regulation of this enzyme to a less-active form contributes to metabolic depression. CS stands as a pace-making enzyme in the first step of the TCA cycle. Diminished CS activity in Cd-treated clams was consistent with the inhibition of CS in Cd-treated oysters (Ivanina et al., 2008), suggesting that the inhibition of CS activity by Cd was probably a common strategy in bivalves to negatively affect TCA cycle. Taken together, the monotonic decreases of HK and Cd suggested that Cd might disrupt glycolysis and TCA cycle by inhibiting those pace-making enzymes.

Glutamine plays a role in a variety of biochemical functions, including protein synthesis, cellular energy, carbon donation, ammonia transport, and precursor to the neurotransmitter glutamate. Furthermore, glutamine could be converted to glutamate, which is used in the intracellular synthesis of GSH. In this work, metabolomic analysis revealed that glutamine decreased when $\mathrm{Cd}$ exposure concentrations exceeded $27 \mu \mathrm{g} / \mathrm{L}$, suggesting the increased demand of glutamine in response to $\mathrm{Cd}$ exposure. $\mathrm{Cd}$ treatment caused depletion of glutamine was also 


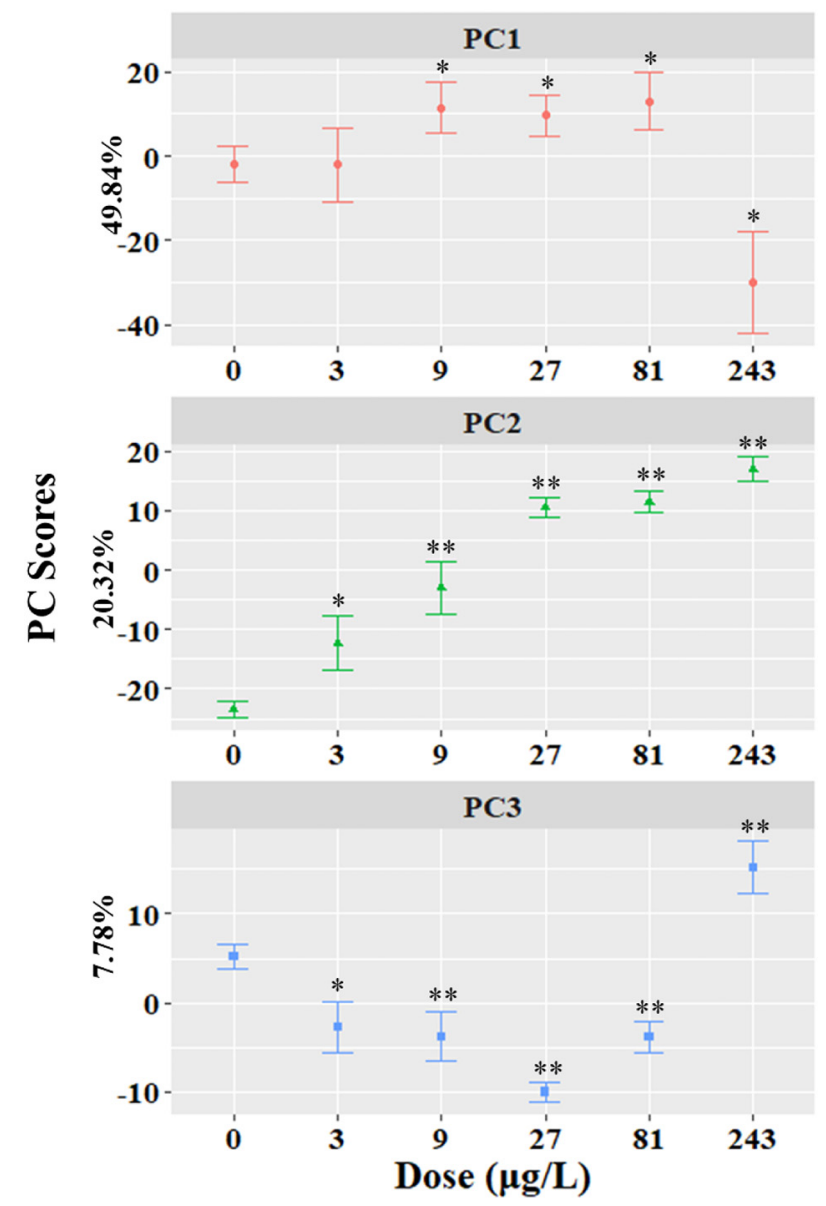

Fig. 3. The average PC scores of control and Cd-treated groups along PC1, PC2 and PC3 axes. PC scores are presented as the mean \pm standard deviation for each group. ${ }^{*}$ and ${ }^{* *}$ indicate significant differences $(P<0.05$ and $P<0.01)$ between control and $C d$ treatment groups.

observed in rats, and supplement of glutamine enabled to protect against cadmium-induced testicular dysfunction in Wister rats (Olaniyi et al., 2020). These findings suggested that glutamine plays an essential role in Cd resistance. G1P in clams was regarded as a sensitive biomarker to Cd, since G1P decreased to a very low level when Cd exposure dose was as low as $3 \mu \mathrm{g} / \mathrm{L}$. Under normal condition, energy supply is sufficiently high to cover the energy costs, and the excess of energy is deposited in storage compounds like glycogen (Sokolova et al., 2012). When organisms are suffering from stresses, energy cost increases in order to cover additional energy demands for detoxification. As glycogen degradation into glucose flows through G1P, the decreases of G1P in Cd-treated clams suggested the consistent consumption of glycogen.

\subsection{Non-monotonic metabolic responses to $\mathrm{Cd}$}

SDH and its substrate succinate showed similar U-shaped responses with the increase of Cd dose. Linking TCA cycle and electron transport system, SDH catalyzes the oxidation of succinate to fumarate and plays a central role in mitochondrial metabolism (Jardim-Messeder et al., 2015). It has been well documented that SDH is the target of Cd (Belyaeva, 2018; Branca et al., 2020) because of its richness of reactive sulfhydryl group (Jay et al., 1991). The inhibition of SDH activity in low concentration ( 9 and $27 \mu \mathrm{g} / \mathrm{L}$ ) of Cd-treated clams was in agreement with those in Cd-treated oysters (Ivanina et al., 2008). However, increases of SDH activity and succinate occurred when Cd exposure concentration ascended to some content. Succinate was one of the end products of anaerobic fermentation (Meng et al., 2016). Therefore, the sharp increase in succinate suggested the induction of anaerobiosis in high concentration $(243 \mu \mathrm{g} / \mathrm{L})$ of Cd-treated group, which was consistent with the strategy of metabolic adaptation to extreme stresses (Sokolova et al., 2012). Succinate was able to protect SDH activity against cadmium ion inhibition (Jay et al., 1991), suggesting that the enhancement of SDH activity in high concentration $(243 \mu \mathrm{g} / \mathrm{L})$ of $\mathrm{Cd}-$ treated group resulted from the increase of succinate.

ALT and its substrate alanine also showed similar U-shaped curves. ALT catalyzes the transfer of amino groups from the alanine to alphaketoglutarate, and the conversion products are glutamate and pyruvate, of which pyruvate can be introduced to TCA cycle for energy production (Moriles and Azer, 2020). The decreases of alanine in low concentrations $(9,27$ and $81 \mu \mathrm{g} / \mathrm{L})$ of Cd-treated groups could be attributed to increased pyruvate demand for TCA cycle. The induction of anaerobiosis was likely responsible for the increase of alanine in high concentration $(243 \mu \mathrm{g} / \mathrm{L})$ of Cd-treated groups, since alanine is an end product of cytosolic anaerobiosis in mollusks (Ivanina et al., 2010). As the last step of glycolysis, PK functions as catalyzing the transfer of phosphate group from phosphoenolpyruvate (PEP) to ADP, yielding one molecule of pyruvate and one molecule of ATP (Gupta and Namezai, 2010). Thus the alteration of ALT and PK activities potentially influenced TCA cycle by regulation of pyruvate supply, and subsequently affected energy homeostasis in resistance to $C d$ stress.

GGT is encoded by CHAC1 and involved in extracellular glutathione metabolism by transferring the glutamyl moiety to a variety of acceptor molecules, leaving the cysteine product to preserve intracellular homeostasis of oxidative stress (Kaur et al., 2017). Located on the outer surface of plasma membrane, GGT plays key roles in GSH homeostasis by breaking down GSH and providing cysteine, the rate-limiting substrate, for intracellular de novo synthesis of GSH (Zhang et al., 2010). Our recent study has found significant up-regulation of CHAC1 expression in high concentration of Cd treatment (data not published), which was consistent with the enzyme activity of GGT. The enhanced GGT activity in the high concentration $(243 \mu \mathrm{g} / \mathrm{L})$ of Cd-treated group suggested an adaptation to increased oxidative stress.

Hormesis describes a dose-response relationship separated into two dose zones, low-dose before the estimated threshold with stimulatory responses, and high-dose after the estimated threshold with inhibitory and/or adverse reaction (Agathokleous and Calabrese, 2020a). Moreover, the maximum low-dose stimulatory response is less than 2-fold of control as a rule (Calabrese et al., 2019). In this work, many endpoints such as SDH, PK, GGT, ALT, alanine, succinate, glucose, AMP, and ATP presented dose-responses approximate to U-shaped or J-shaped curves, and the maximum low-dose stimulatory responses of some endpoints were in agreement with the hormesis rule. Especially, succinate and $\mathrm{SDH}$ activity presented typical hormetic dose-response curves. Hormesis represents an overcompensation to a disruption in homeostasis. Lowdose effects extend the energy supply, which enables to adapt more severe stress (Agathokleous and Calabrese, 2020b). The induction of anaerobiosis indicated by a sharp increase in succinate exactly extended the energy supply and was definitely recognized as hormetic effects on metabolism. However, not all U-shaped or J-shaped curves could be regarded as hormesis despite its generalization (Agathokleous and Calabrese, 2019). Of these endpoints in this work, some U-shaped responses lacked plenty of doses with significance $(P<0.05)$ in stimulatory responses or in inhibitory responses and failed to match hormesis, which reminds us of carefully designing the exposure doses in lowdose zone.

\subsection{Monotonic responses of histopathological condition indices}

Stresses enable organisms to re-establish homeostasis of metabolism. However, a death program (apoptosis) or even necrosis will occur when tolerance limits are exceeded and irreversible breakdown arrives (Kultz, 2020). Chronic exposure or high doses of effectors might induce tissue injuries. In this work, injuries occurred in two 


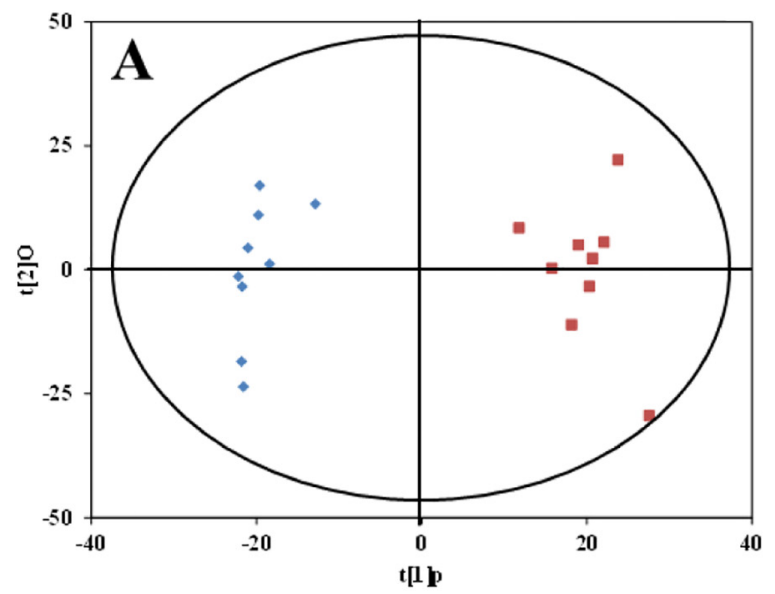

$R^{2} X=71.7 \%, Q^{2}=0.948$

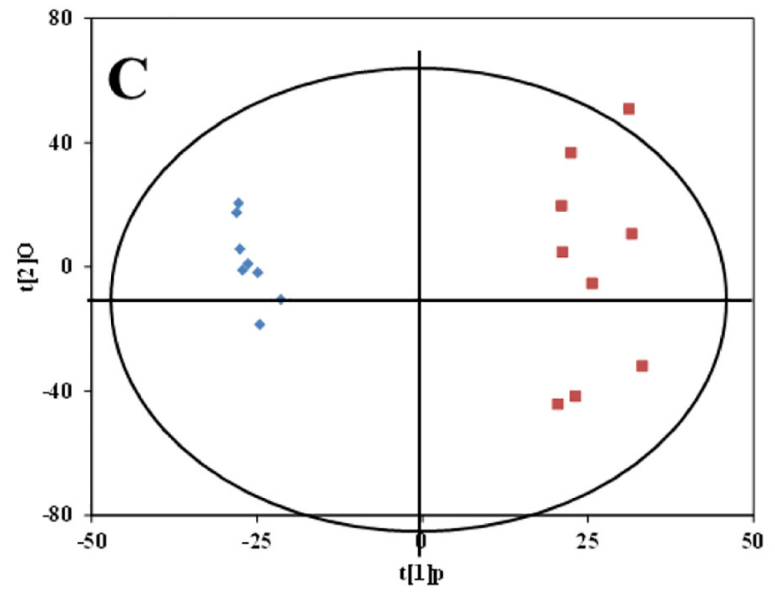

$R^{2} X=80.9 \%, Q^{2}=0.978$

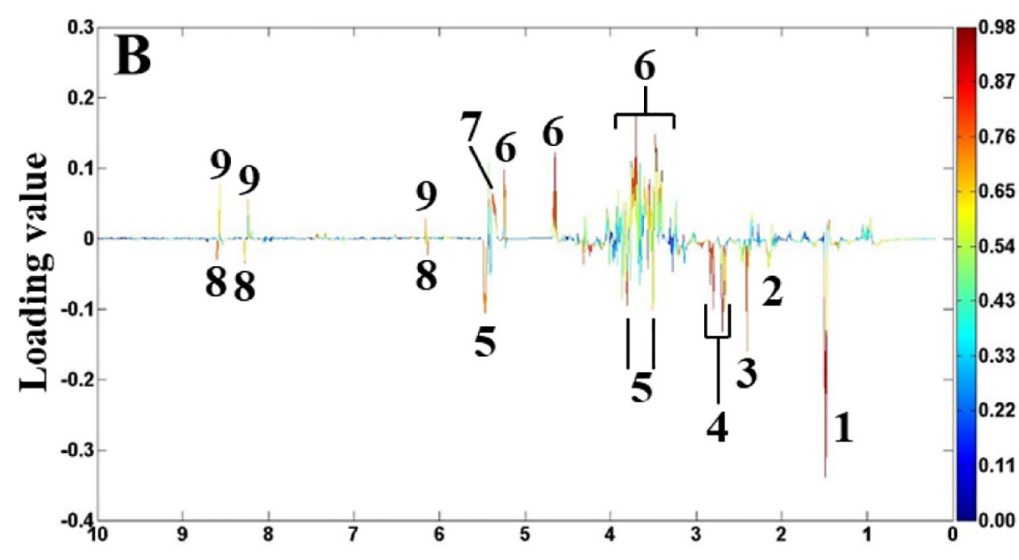

Chemical shift (ppm)

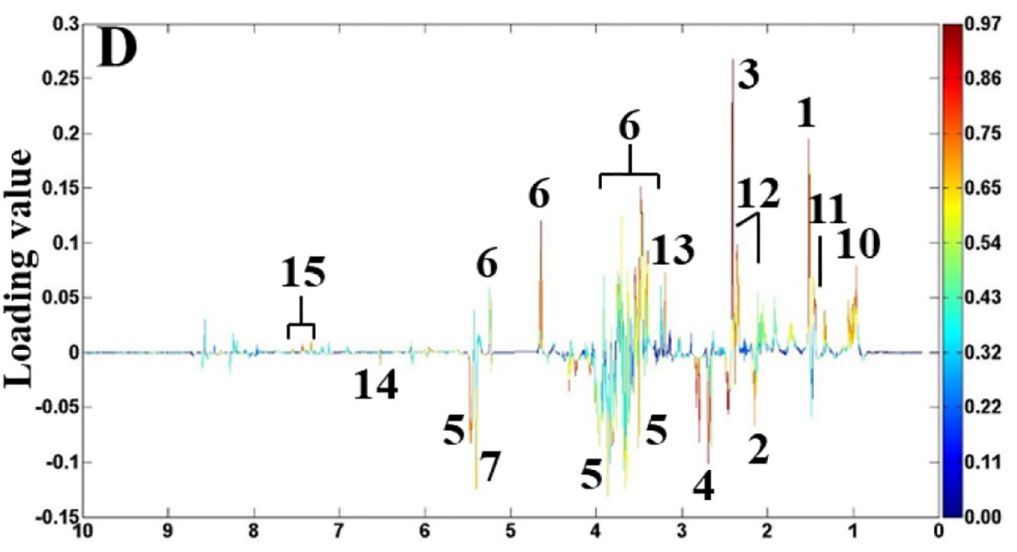

Chemical shift (ppm)

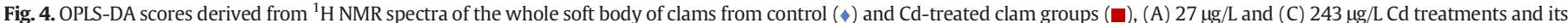

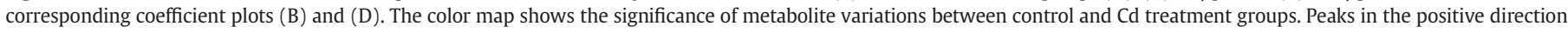

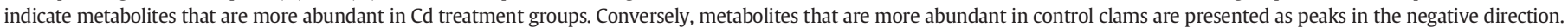

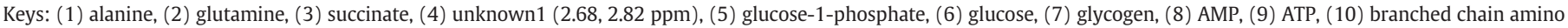
acids (BCAAs), (11) threonine, (12) glutamate, (13) choline, (14) fumarate, (15) phenylalanine.

typical and key organs, gill and hepatopancreas, after Cd exposure for 14 days. In bivalve, gill is an important organ for breath and filtration, and hepatopancreas plays essential roles in digestion and detoxification. Both gill and hepatopancreas are typical targets of marine contaminants (Dallares et al., 2018; Luna-Acosta et al., 2015). Cd treatments induced significant histological alterations of gill and hepatopancreas in clams treated with higher concentrations $(27,81$, and $243 \mu \mathrm{g} / \mathrm{L})$ of $\mathrm{Cd}$. $\mathrm{HCI}$ evaluation enables to quantify the histopathological observations and is well applied in injury description (Costa et al., 2013). The BMD analysis on HCIs showed that the BMD value of hepatopancreas $\mathrm{HCI}$ was smaller than those of gill $\mathrm{HCI}$, suggesting that hepatopancreas was more sensitive to $\mathrm{Cd}$ exposure than gill. The susceptibility of hepatopancreas to Cd could be interpreted by its involvement in metals accumulation and detoxification (Sokolova et al., 2005a; Truchet et al., 2020). Overall, hepatopancreas of clam is a preferable organ biomarker to $\mathrm{Cd}$ pollution.

\subsection{Biomarkers selection and risk assessment}

In the past decades, BMD method has been increasingly used to assess health risk of environmental contaminants. Characterization of dose-response relationships and calculation of BMD values allow for selection of preferable biomarkers. Theoretically, those endpoints presenting monotonic curves and relatively low BMD values were potentially preferable biomarkers in clams to Cd. Accordingly, the metabolite glutamine and the enzyme CS in this work were preferable biomarkers to $\mathrm{Cd}$ exposure.

However, due to assumption of a monotonic dose-response relationship, BMD method has a poor capacity of model fitting on those endpoints presenting non-monotonic curves (Smetanova et al., 2015). In this work, many endpoints such as G1P, glucose, ATP, SDH, and PK failed to be fitted to a BMD dose-response curve because of nonsignificant trend or non-monotonic response to $\mathrm{Cd}$ exposure. Considering exposure to pollutants below the threshold where hormetic stimulation prevails, ignoring hormesis indeed causes a gap between the guideline of ecological risk assessment and reality in ecological risk assessment (Zhang and Lin, 2020). The good news is that major regulatory agencies like U.S. EPA have proposed to consider non-linear biphasic doseresponse models (Agathokleous et al., 2019). The overall consideration on multiple dose responses including hormesis will improve the quality of hazard and risk assessment (Agathokleous and Calabrese, 2020a,b).

\section{Conclusion}

In this work, the dose-dependent effects of Cd on metabolism in clams were studied by metabolomic profiling, enzyme measurement, 


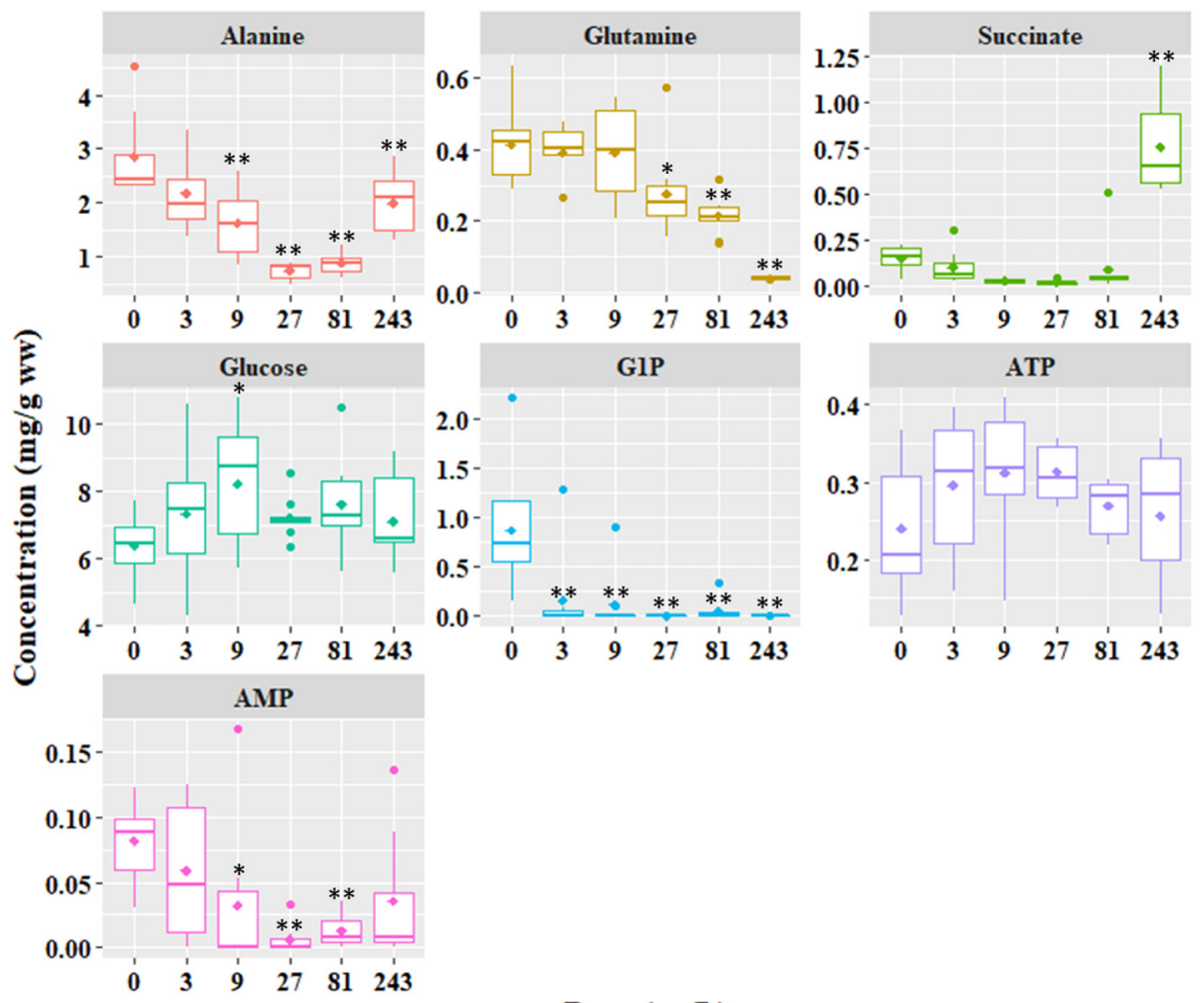

Dose $(\mu \mathrm{g} / \mathrm{L})$

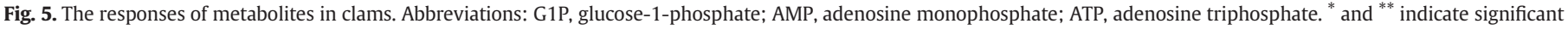
differences $(P<0.05$ and $P<0.01)$ between control and $C d$ treatment groups.

and quantification of tissue injury. We found that the responses of metabolites and metabolic enzymes associated with glycolysis, TCA cycle, amino acid metabolism/synthesis, and OXPHOS presented both monotonic and non-monotonic curves with the increase of $\mathrm{Cd}$ dose. Monotonic decreases of HK and CS activities suggested Cd exposure potentially disrupted glycolysis and TCA cycle via inhibiting rate-limiting enzymes. SDH, ALT, and their substrates presented non-monotonic responses approximate to U- or J-shaped curves, suggesting the adaptive strategy of metabolic responses to different degrees of Cd stress, like induction of anaerobiosis as energy compensation. Especially, the alterations of succinate and SDH presented typical hormetic dose-response curves. BMD analysis revealed that clam hepatopancreas tissue was more sensitive to $\mathrm{Cd}$ than gill tissue in terms of injury occurrence.
What is more, glutamine and CS were preferable biomarkers to Cd exposure due to their monotonic responses and relatively lower BMD values. Overall, characterization of dose-dependent effect of $\mathrm{Cd}$ on metabolism and tissue injuries provides a new insight into understanding the metabolic adaptation in marine clams and risk assessment of $\mathrm{Cd}$ pollution.

\section{Ethical statement}

All procedures were strictly performed according to the Guidelines of the Chinese Council on Laboratory Animal Care (2001), which was approved by the Animal Research Ethics Board of Chinese Academy of Sciences.

Table 1

Metabolites and enzymes $(n=9)$ in clam whole soft tissues and histopathological condition indices (HCIs) $(n=4)$ of clam gills and hepatopancreas.

\begin{tabular}{|c|c|c|c|c|c|c|c|c|c|}
\hline Cd exposure $(\mu \mathrm{g} / \mathrm{L})$ & & Control & 3 & 9 & 27 & 81 & 243 & BMD & BMDL \\
\hline \multirow[t]{7}{*}{ Metabolites (mg/g ww) } & Ala & $1.52 \pm 0.41$ & $1.17 \pm 0.38$ & $0.87 \pm 0.33^{* *}$ & $0.40 \pm 0.08^{* *}$ & $0.48 \pm 0.11^{* *}$ & $1.07 \pm 0.31^{* *}$ & PMF & PMF \\
\hline & Gln & $0.36 \pm 0.09$ & $0.34 \pm 0.07$ & $0.34 \pm 0.11$ & $0.24 \pm 0.11^{*}$ & $0.19 \pm 0.05^{* *}$ & $0.03 \pm 0.01^{* *}$ & 17.87 & 8.26 \\
\hline & Suc & $0.11 \pm 0.05$ & $0.07 \pm 0.06$ & $0.02 \pm 0.01$ & $0.02 \pm 0.01$ & $0.07 \pm 0.11$ & $0.53 \pm 0.18^{* *}$ & PMF & PMF \\
\hline & Glu & $6.90 \pm 1.06$ & $7.92 \pm 1.92$ & $8.88 \pm 1.88^{*}$ & $7.82 \pm 0.66$ & $8.21 \pm 1.48$ & $7.66 \pm 1.42$ & PMF & PMF \\
\hline & G1P & $1.38 \pm 0.98$ & $0.26 \pm 0.67^{* *}$ & $0.18 \pm 0.47^{* *}$ & $\mathrm{ND}^{* *}$ & $0.09 \pm 0.17^{* *}$ & $\mathrm{ND}^{* *}$ & PMF & PMF \\
\hline & ATP & $0.73 \pm 0.26$ & $0.90 \pm 0.26$ & $0.95 \pm 0.25^{*}$ & $0.95 \pm 0.11$ & $0.82 \pm 0.11$ & $0.78 \pm 0.25$ & PMF & PMF \\
\hline & AMP & $0.17 \pm 0.06$ & $0.12 \pm 0.10$ & $0.07 \pm 0.11^{*}$ & $0.01 \pm 0.02^{* *}$ & $0.03 \pm 0.03^{* *}$ & $0.07 \pm 0.10$ & PMF & PMF \\
\hline \multirow[t]{6}{*}{ Enzymes } & CS & $9.91 \pm 1.50$ & $9.34 \pm 1.30$ & $8.14 \pm 2.53$ & $7.12 \pm 3.33$ & $6.42 \pm 2.30^{*}$ & $7.17 \pm 1.47$ & 10.67 & 2.22 \\
\hline & SDH & $10.92 \pm 3.82$ & $10.32 \pm 1.85$ & $7.35 \pm 3.61$ & $4.87 \pm 1.86^{*}$ & $9.53 \pm 4.98$ & $15.64 \pm 3.53$ & PMF & PMF \\
\hline & HK & $54.52 \pm 17.22$ & $53.52 \pm 4.96$ & $42.72 \pm 25.68$ & $29.66 \pm 8.36^{* *}$ & $32.76 \pm 15.69^{*}$ & $30.65 \pm 10.83^{*}$ & PMF & PMF \\
\hline & PK & $78.75 \pm 15.24$ & $66.03 \pm 7.25$ & $55.27 \pm 22.14$ & $56.41 \pm 16.99$ & $71.71 \pm 22.95$ & $65.29 \pm 22.95$ & PMF & PMF \\
\hline & GGT & $1.65 \pm 0.58$ & $1.51 \pm 0.33$ & $1.19 \pm 0.45$ & $1.40 \pm 0.46$ & $1.45 \pm 0.47$ & $2.35 \pm 0.81$ & 209.92 & 113.01 \\
\hline & ALT & $75.65 \pm 22.49$ & $74.97 \pm 7.69$ & $54.92 \pm 25.79$ & $45.65 \pm 13.59^{*}$ & $54.41 \pm 13.68$ & $60.83 \pm 13.70$ & 20.07 & 9.10 \\
\hline \multirow[t]{2}{*}{$\mathrm{HCls}$} & Hepa & $0.07 \pm 0.03$ & $0.08 \pm 0.04$ & $0.11 \pm 0.02$ & $0.30 \pm 0.04^{* *}$ & $0.40 \pm 0.09^{* *}$ & $0.69 \pm 0.10^{* *}$ & 8.32 & 5.44 \\
\hline & Gill & $0.06 \pm 0.03$ & $0.10 \pm 0.05$ & $0.13 \pm 0.03$ & $0.18 \pm 0.10^{*}$ & $0.38 \pm 0.06^{* *}$ & $0.64 \pm 0.06^{* *}$ & 11.11 & 8.02 \\
\hline
\end{tabular}

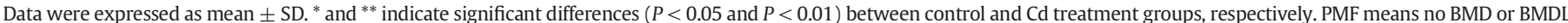

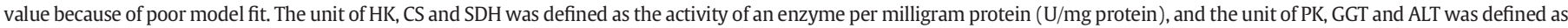

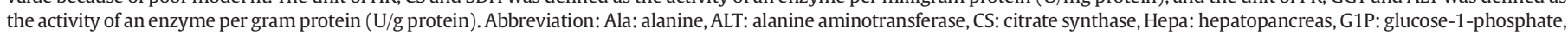
GGT: gamma-glutamyl transpeptidase, Gln: glutamine, Glu: glucose, HK: hexokinase, PK: pyruvate kinase, SDH: succinate dehydrogenase, Suc: succinate. 


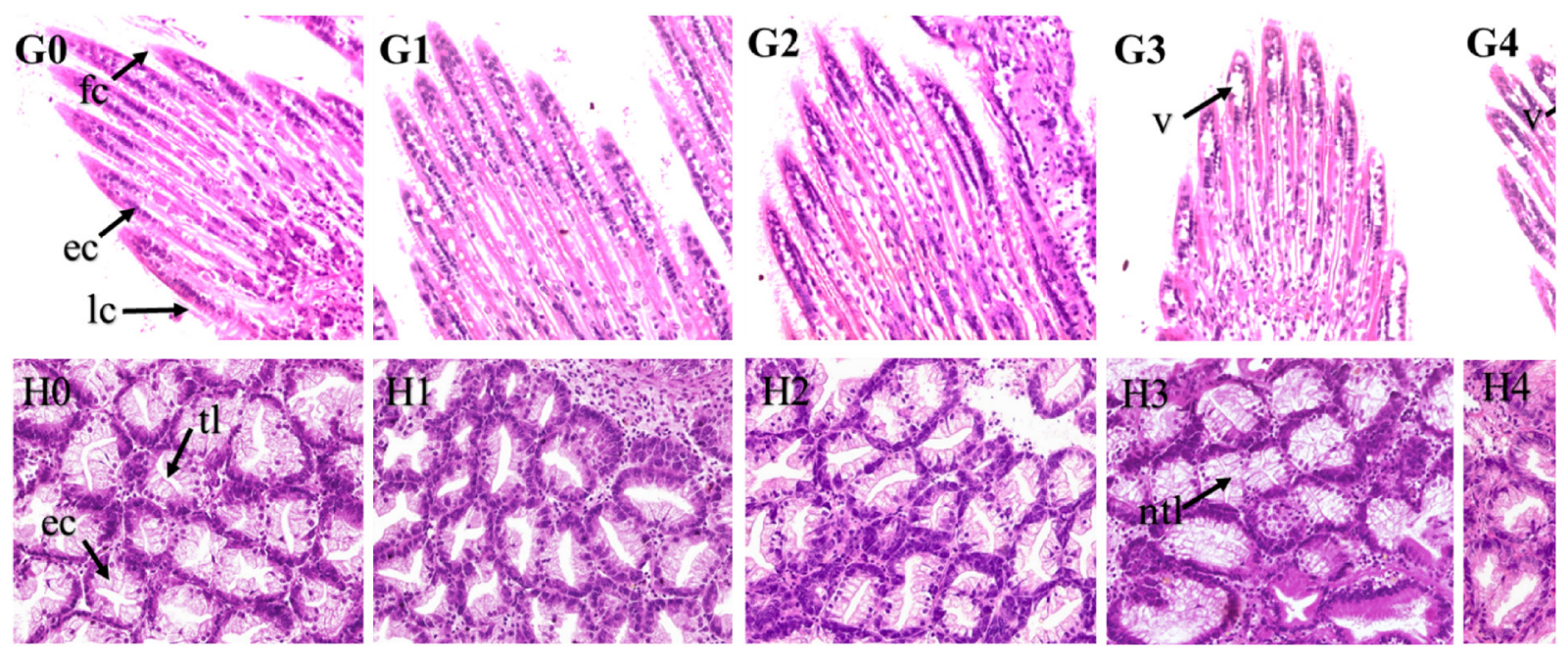

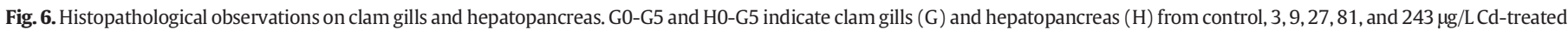
groups, respectively. Abbreviations: A, atrophy; ec, epithelial cell; fc, frontal cilia; h, haemocyte; lc, lateral cilia; n, necrosis; ntl, narrowed tubular lumen; tl, tubular lumen; v, vacuole.

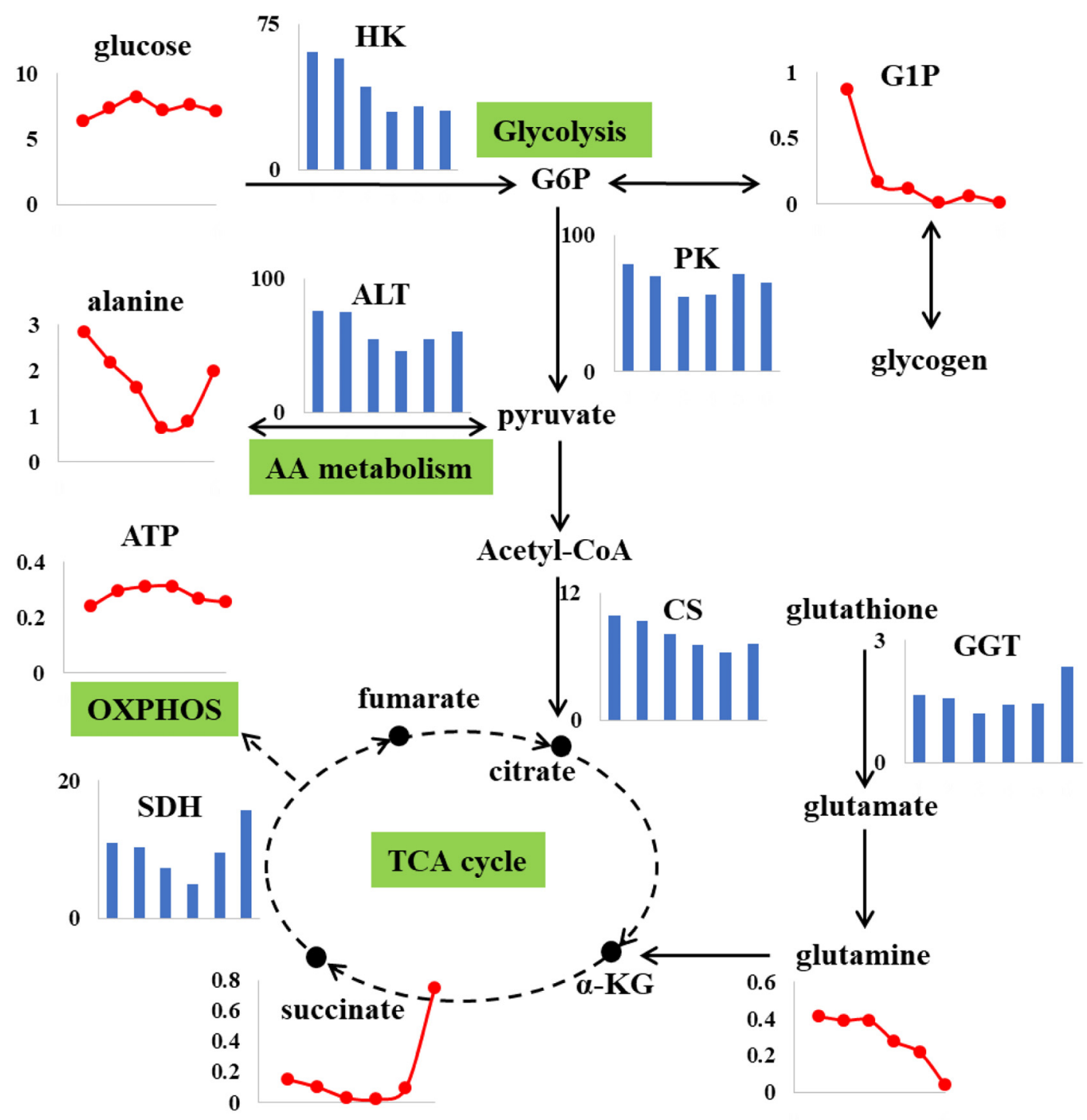

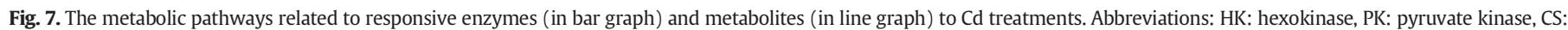
citrate synthase, SDH: succinate dehydrogenase, GGT: gamma-glutamyl transpeptidase, ALT: alanine aminotransferase. 


\section{CRediT authorship contribution statement}

Junfei Zhan: Formal analysis, Writing - original draft. Shuang Wang: Writing - review \& editing. Fei Li: Writing - review \& editing. Chenglong Ji: Funding acquisition, Writing - review \& editing. Huifeng Wu: Funding acquisition, Writing - review \& editing, Project administration.

\section{Declaration of competing interest}

We declare that we have no conflicts of interest to this work.

\section{Acknowledgement}

This research was supported by the grants from National Natural Science Foundation of China (42076164 and 41676114) and the Young Taishan Scholars Program of Shandong Province for Prof. Huifeng Wu (tsqn201812115).

\section{Appendix A. Supplementary data}

Supplementary data to this article can be found online at https://doi. org/10.1016/j.scitotenv.2021.146479.

\section{References}

Agathokleous, E., 2018. Environmental hormesis, a fundamental non-monotonic biological phenomenon with implications in ecotoxicology and environmental safety. Ecotoxicol. Environ. Saf. 148, 1042-1053.

Agathokleous, E., Calabrese, E.J., 2019. Hormesis: the dose response for the 21st century: the future has arrived. Toxicology 425, 152249.

Agathokleous, E., Calabrese, E.J., 2020a. A global environmental health perspective and optimisation of stress. Sci. Total Environ. 704, 135263.

Agathokleous, E., and Calabrese, E.J., 2020b. Envrionmental toxicology and ecotoxicology: how clean is clean? Rethinking dose-response analysis. Sci Total Environ 704, 135263. 138769.

Agathokleous, E., Anav, A., Araminiene, V., De Marco, A., Domingos, M., Kitao, M., Koike, T., Manning, W.J., Paoletti, E., Saitanis, C.J., Sicard, P., Vitale, M., Wang, W., Calabrese, E.J., 2019. Commentary: EPA's proposed expansion of dose-response analysis is a positive step towards improving its ecological risk assessment. Environ. Pollut. 246, 566-570.

Belyaeva, E.A., 2018. Respiratory complex II in mitochondrial dysfunction-mediated cytotoxicity: insight from cadmium. J Trace Elem Med Bio 50, 80-92.

Bernet, D., Schmidt, H., Meier, W., Burkhardt-Holm, P., Wahli, T., 1999. Histopathology in fish: proposal for a protocol to assess aquatic pollution. J. Fish Dis. 22, 25-34.

Branca, J.J.V., Pacina, A., Gulisano, M., Taddei, N., Fiorillo, C., Becatti, M., 2020. Cadmiuminduced cytotoxicity: effects on mitochondrial electron transport chain. Front Cell Dev Biol 8, 1428.

Burke, J.J., Siedow, J.N., Moreland, D.E., 1982. Succinate dehydrogenase. Plant Physiol. 70, 1577-1581.

Calabrese, E.J., 2008. Hormesis: why it is important to toxicology and toxicologists. Environ. Toxicol. Chem. 27, 1451-1474.

Calabrese, E.J., Agathokleous, E., Kozumbo, W.J., Stanek III, E.J., Leonard, D., 2019. Estimating the range of the maximum hermetic stimulatory response. Environ. Res. 170, 337-343.

Chen, L., Wu, H., Zhao, J., Zhang, W., Zhang, L., Sun, S., Yang, D., Cheng, B., Wang, Q., 2018. The role of GST omega in metabolism and detoxification of arsenic in clam Ruditapes philippinarum. Aquat. Toxicol. 204, 9-18.

Costa, P.M., Carreira, S., Costa, M.H., Caeiro, S., 2013. Development of histopathological indices in a commercial marine bivalve (Ruditapes decussatus) to determine environmental quality. Aquat. Toxicol. 126, 442-454.

Dallares, S., Carrasco, N., Alvarez-Munoz, D., Rambla-Alegre, M., Sole, M., 2018. Multibiomarker biomonitoring approach using three bivalve species in the Ebro Delta (Catalonia, Spain). Environ Sci Pollut R 25, 36745-36758.

Du, B., Zhou, J., Lu, B., Zhang, C., Li, D., Zhou, J., Jiao, S., Zhao, K., Zhang, H., 2021. Environmental and human health risks from cadmium exposure near an active lead-zinc mine and a copper smelter, China. Sci. Total Environ. 720, 137585.

Else, A.J., Barnes, S.J., Danson, M.J., Weitzman, P.D., 1988. A new spectrophotometric assay for citrate synthase and its use to assess the inhibitory effects of palmitoyl thioesters. Biochem. J. 251, 803-807.

Fu, J., Wang, H., Billah, S.M.R., Yu, H., Zhang, X., 2014. Heavy metals in seawater, sediments, and biota from the coastal area of Yancheng city, China. Environ. Toxicol. Chem. 33, 1697-1704.

Gupta, V., Namezai, R.N.K., 2010. Human pyruvate kinase M2: a multifunctional protein. Protein Sci. 19, 2031-2044.

Gutman, I., Bernt, E., 1974. Pyruvate kinase assay in serum and erythrocytes. In: Bergmeyer, H.U. (Ed.), Method of Enzymatic Analysis, Second edition Academic Press Inc, Cambridge, pp. 774-778.

Hardy, A., Benford, D., Halldorsson, T., Jeger, M.J., Knutsen, K.H., More, S., Mortensen, A., Naegeli, H., Noteborn, H., Ockleford, C., Ricci, A., Rychen, G., Silano, V., Solecki, R., Turck, D., Aerts, M., Bodin, L., Davis, A., Edler, L., Gundert-Remy, U., Sand, S., Slob,
W., Bottex, B., Abrahantes, J.C., Marques, D.C., Kass, G., Schlatter, J.R., 2017. Update: use of the benchmark dose approach in risk assessment. EFSA J. 15, e04658.

Ivanina, A.V., Habinck, E., Sokolova, I.M., 2008. Differential sensitivity to cadmium of key mitochondrial enzymes in the eastern oyster, Crassostrea virginca Gmelin (Bivalvia: Ostreidae). Comp Biochem Phys C 148, 72-79.

Ivanina, A.V., Sokolov, E.P., Sokolova, I.M., 2010. Effects of cadmium on anaerobic energy metabolism and mRNA expression during air exposure and recovery of an intertidal mollusk Crassostrea virginica. Aquat. Toxicol. 99, 330-342.

Jardim-Messeder, D., Caverzan, A., Rauber, R., Ferreira, E.D., Margis-Pinheiro, M., Galina, A., 2015. Succinate dehydrogenase (mitochondrial complex II) is a source of reactive oxygen species in plants and regulates development and stress responses. New Phytol. 208, 776-789.

Jay, D., Zamorano, R., Munoz, E., Gleason, R., Boldu, J.L., 1991. Study of the interaction of cadmium with membrane-bound succinate-dehydrogenase. J. Bioenerg. Biomembr. 23, 381-389.

Ji, C., Yu, D., Wang, Q., Li, F., Zhao, J., Wu, H., 2016. Impact of metal pollution on shrimp Crangon affinis by nmr-based metabolomics. Mar. Pollut. Bull. 106, 372-376.

Ji, C., Lu, Z., Xu, L., Li, F., Cong, M., Shan, X., Wu, H., 2019. Evaluation of mitochondrial toxicity of cadmium in clam Ruditapes philippinarum using itraq-based proteomics. Environ. Pollut. 251, 802-810.

Kaur, A., Gautam, R., Srivastava, R., Chandel, A., Kumar, A., Karthikeyan, S., Bachhawat, A.K., 2017. ChaC2, an enzyme for slow turnover of cytosolic glutathione. J. Biol. Chem. 292, 638-651.

Krishnakumar, P.K., Qurban, M.A., Sasikumar, G., 2018. Biomonitoring of trace metals in the coastal waters using bivalve molluscs. In: El-Din, H., Saleh, M., El-Adham, E. (Eds.), Trace Elements-Human Health and Environment. IntechOpen, London, pp. 153-176.

Kultz, D., 2020. Defining biological stress and stress responses based on principles of physics. J. Exp. Zool. 333, 350-358.

Lin, X., Xu, W., 2016. Hexokinase is a key regulator of energy metabolism and ROS activity in insect lifespan extension. Aging 8, 245-259.

Liu, F., Lu, Z., Wu, H.F., Ji, C.L., 2019. Dose-dependent effects induced by cadmium in polychaete Perinereis aibuhitensis. Ecotox Environ Safe 169, 714-721.

Luna-Acosta, A., Bustamante, P., Budzinski, H., Huet, V., Thomas-Guyon, H., 2015. Persistent organic pollutants in a marine bivalve on the Marennes-Oleron Bay and the Gironde Estuary (French Atlantic Coast)-part 2: potential biological effects. Sci. Total Environ. 514, 511-522.

Meister, A., Tate, S.S., Griffith, O.W., 1981. $\gamma$-Glutamyl transpeptidase. Method Enzymol 77, 237-253.

Meng, J., Wang, B., Liu, D., Chen, T., Wang, Z., Zhao, X., 2016. High-yield anaerobic succinate production by strategically regulating multiple metabolic pathways based on stoichiometric maximum in Escherichia coli. Microb. Cell Factories 15, 141.

Moriles, K.E., Azer, S.A., 2020. Alanine amino transferase. In: StatPearls [Internet]. StatPearls Publishing, Treasure Island (FL) https://www.ncbi.nlm.nih.gov/books/ NBK559278/. (Accessed 28 February 2021).

Noor, M.N., Wu, F., Sokolov, E.P., Falfushynska, H.F., Timm, S., Haider, F., Sokolova, I.M., 2021. Salinity-dependent effects of $\mathrm{ZnO}$ nanopariticles on bioenergetic and intermediate metabolite homeostasis in a euryhaline marine bivalve, Mytilus edulis. Sci. Total Environ. 774, 145195.

Olaniyi, K.S., Amusa, O.A., Oniyide, A.A., Ajadi, I.O., Akinnagbe, N.T., Babatunde, S.S., 2020. Protective role of glutamine against cadmium-induced testicular dysfunction in wistar rats: involvement of G6PD activity. Life Sci 242

Ramírez-Bajo, M.J., de Atauri, P., Ortega, F., Westerhoff, H.V., Gelpí, J.L., Centelles, J.J., Cascante, M., 2014. Effects of cadmium and mercury on the upper part of skeletal muscle glycolysis in mice. PLoS One 9, e80018.

Scheer, W.D., Lehmann, H.P., Beeler, M.F., 1978. An improved assay for hexokinase activity in human tissue homogenates. Anal. Biochem. 91, 451-463.

Smetanova, S., Riedl, J., Zitzkat, D., Altenburger, R., Busch, W., 2015. High-throughput concentration-response analysis for omics datasets. Environ. Toxicol. Chem. 34, 2167-2180.

Sokolova, I.M., Ringwood, A.H., Johnson, C., 2005a. Tissue-specific accumulation of cadmium in subcellular compartments of eastern oysters Crassotrea virginica Gmelin (Bivalvia: Ostreidae). Aquat. Toxicol. 74, 218-228.

Sokolova, I.M., Sokolov, E.P., Ponnappa, K.M., 2005b. Cadmium exposure affects mitochondrial bioenergetics and gene expression of key mitochondrial proteins in the eastern oyster Crassostrea virginica Gmelin (Bivalvia: Ostreidae). Aquat. Toxicol. $73,242-255$.

Sokolova, I.M., Frederich, M., Bagwe, R., Lannig, G., Sukhotin, A.A., 2012. Energy homeostasis as an integrative tool for assessing limits of environmental stress tolerance in aquatic invertebrates. Mar. Environ. Res. 79, 1-15.

Truchet, D.M., Buzzi, N.S., Simonetti, P., Marcovecchio, J.E., 2020. Uptake and detoxification of trace metals in estuarine crabs: insight into the role of metallothioneins. Environ. Sci. Pollut. Res. 27, 31905-31917.

UN Environmental Programme, 2020. UNEP's activities on lead and cadmium. https:// www.unep.org/explore-topics/chemicals-waste/what-we-do/emerging-issues/leadand-cadmium. (Accessed 28 February 2021).

US EPA, 2012. Benchmark dose technical guidance. https://www.epa.gov/risk/benchmark-dose-technical-guidance. (Accessed 28 February 2021).

Wignall, J.A., Shapiro, A.J., Wright, F.A., Woodruff, T.J., Chiu, W.A., Guyton, K.Z., Rusyn, I., 2014. Standardizing benchmark dose calculations to improve science-based decisions in human health assessments. Environ. Health Perspect. 122, 499-505.

Wilkinson, J.H., Baron, D.N., Moss, D.W., Walker, P.G., 1972. Standardization of clinical enzyme assays: a reference method for asparate and alanine transaminases. J Clin Path $25,940-944$ 
Wu, H., Wang, W.-X., 2010. NMR-based metabolomic studies on the toxicological effects of cadmium and copper on green mussels Perna viridis. Aquat. Toxicol. 100, 339-345.

Wu, H., Ji, C., Wang, Q., Liu, X., Zhao, J., Feng, J., 2013. Manila clam Venerupis philippinarum as a biomonitor to metal pollution. Chin J Oceanol Limn 31, 65-74.

Xie, M., Dai, H., Liu, J., Xue, Z., Chen, Y., Liang, X., Mou, H., Sun, H., Li, Y., Chen, W., 2020. Metabolomics reveals the "invisible" detoxification mechanisms of Amaranthus hypochondriacus at three ages upon exposure to different levels of cadmium. Ecotox Environ Safe 195.
Xu, L., Ji, C., Zhao, J., Wu, H., 2016. Metabolic responses to metal pollution in shrimp Crangon affinis from the sites along the Laizhou Bay in the Bohai Sea. Mar. Pollut. Bull. 113, 536-541.

Zhang, X., Lin, Z., 2020. Hormesis-induced gap between the guidelines and reality in ecological risk assessment. Chemosphere 243, 125348.

Zhang, Y., Song, J., Yuan, H., Xu, Y., He, Z., 2010. Concentrations of cadmium and zinc in seawater of Bohai Bay and their effects on biomarker responses in the bivalve Chlamys farreri. Arch. Environ Contam Toxicol 59, 120-128. 